\title{
Prevalence of Intestinal Parasites among School Children in Uzo- Uwani Local Governemnt Area of Enugu State
}

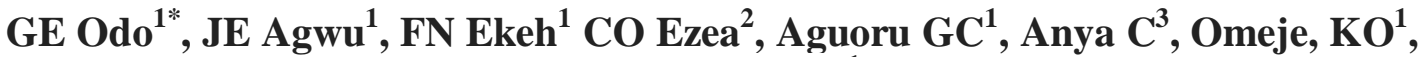 \\ Ubachukwu PO ${ }^{1}$ \\ ${ }^{1}$ Department of Zoology and Environmental Biology, University of Nigeria \\ ${ }^{2}$ Federal University of Technology, Owerri \\ ${ }^{3}$ Gregory University Uturu, Okigwe, Imo State \\ *gregory.odo@unn.edu.ng
}

\begin{abstract}
Intestinal parasitic infections have always been an important public health problem in the tropics particularly in developing countries. A cross-sectional survey involving 200 school going children of both sex aged 5-19 years was conducted in 3 secondary and 1 primary schools at different locations in Uzo-uwani Local Govern Area (L.G.A) of Enugu State, Nigeria, between May and July, 2016, to determine the prevalence of intestinal parasites. Among the 200 samples examined 105 (52.5\%) were infected with different intestinal parasites. The parasites found were Hookworm, A. lumbricoides, T. trichuria, E. histolytic and G.lamblia with prevalence of 28(14.0\%), 28(14.0\%), 23(11.5\%), 21(10.5\%), and 17(8.5\%) respectively. Hookworm and A. lumbricoides had highest prevalence 28(14.0\%) while G. lambla had lowest 17(8.5\%). Premier Primary School, Ukpabi-Nibo had highest prevalence 29(58.0\%) and Welfare Secondary School, Opanda had lowest 24(48.0\%). Result showed that there is a direct link between ones' hygiene and prevalence. The prevalence of intestinal parasites in relation to sex showed no significant difference $(p<0.05)$ as they have equal exposure. Also the prevalence in relation to age group was statistically insignificant $(p>0.05)$. However there was slight decline in prevalence as the age increased.
\end{abstract}

\section{INTRODUCTION AND LITERATURE REVIEW}

\subsection{Introduction}

Gastrointestinal parasites are micro-organisms that live in the intestine, some cause problem while others can live for long periods in the bowel without causing any symptoms or require treatment (Eleni et al., 2014).

Gastrointestinal parasite and severity of its infections have a profound impact on human public health and development, affecting approximately one-third of the world's population, causing high mortality rate mostly in children (Childer et al., 2014). They can be largely categorized into two groups, protozoans (e.g. Entamoeba histolytical, Giardia duodenalis, Trichomonas horminis, Balatidium coli etc) and helminthes (e.g. Ascaris lumobricoides, Trichuris trichiura, Nesator americanus etc). these GIPs flourish in settings characterized by warm temperature, humidity, poor sanitation, dirty water and crowded housing (Michael et al., 2010).

Silva et al., (2003); Brooker et al., (2006) Stated that the global prevalence of intestinal parasitic infections rate are highest in children living in sub-Sahara Africa, followed by Asia and then Latin America and the Caribbean. According to Brookeer (2006) in sub-sub-Sahara Africa, it was estimated that approximately a quarter of the total population was infected with one or more helminthes, typically the nematodes worms which are the most prevalence of all gastrointestinal parasites. The 2006 estimates propose that of the then 181 million school-aged children in sub-Sahara Africa, almost half ( 89 million) were affected by one more of these parasitic worm he further added.

The burden of diseases caused by intestinal worms is a major public health problem. Indeed, it has been estimated that children aged 5-14 years in low income countries, intestinal worms infection account for $12 \%$ of total disability adjusted life years (DALYs) lost due to communicable disease among school children as a result of intestinal nematodes. The public-health and socio-economic consequence of intestine helminthes are of considerable global concern especial in the children health and development where it cause malnutrition, which compromise their learning capabilities in their 
formative years (Absar et al., 2010). In Sub-Sahara Africa, intestinal helminthes are the most common and diseases with a very higher negative public health and socio-economic impact (Enimien et al., 2014).

The transmission of this intestinal parasites infection has behavioral, environmental and biological bases (Michael et al., 2010). For instance children tend to be more active in infected environment and rarely employ good sanitary behaviour; also these potential carriers are crowded together for a long period of time (e.g. in school, orphanage or slum); in addition helminthes are masterful immunoregulator and able to elicit a complex and mixed $\mathrm{Th}_{1} / \mathrm{Th}_{2}$ respond that both ward off and subverts an immune response from the host.

Most of parasitological survey of common parasitic infections in Nigeria has been confined to rural villages, where poor sanitation and hygiene as well as a general ignorance of the disease, provide optimal environment for transmission (Damen et al., 2010).

In small villages of Nigeria, the parasitic disease burden on school children has been shown to be high even though many of the infections may not cause disease or mortality (Onyish and Okafor, 2005).

Prevalence of intestinal parasites in some communities and schools in Enugu State has been investigated on, but data on the intestinal parasites of school-aged children in Uzo Uwani L.G.A could be lacking. Thus this study is designed to gather information on the prevalence of intestinal parasites status and identification of the local risk factors associated with the prevalence in school age children in Uzo Uwani LGA, hence, providing the baseline information which may aid to medical intervention in form of sanitation and chemotherapy.

The aim of this study was to find out the prevalence of intestinal parasites; find out the correlation between intestinal parasitic infections and some associated local risk factors among school going children (5-19 years) in Uzo-Uwani L.G.A. of Enugu State and based on the findings of this study, preventive and control measures are to be suggested.

\section{MATERIAL AND MeTHODS}

\subsection{Study Area}

This study used a cross-sectional design to determine the prevalence of intestinal parasites among school children in different schools in Uzo-uwani Local Government Area from May to July 2016.

Uzo-Uwani is one of the Local Government Areas in Enugu State, Nigeria. This Local Government Area encompasses an area of total $855 \mathrm{Km}^{2}$ (330sqmi) and cover areas within latitude $6^{0} 30$ to $6^{0} 50 \mathrm{~N}$ and longitude $7^{\circ} 00 \mathrm{E}$ and $730^{\circ} \mathrm{E}$. It has a population of 124,480 at 2006 census and bordering Anambra State, Ojebe Ogene L.G.A., Udi L.G.A., Nsukka L.G.A. and Igbo Etiti L.G.A. of Enugu state.

People in this L.G.A. are mainly farmers. The favorable and rich soil of this area encourages largescale agriculture. Their major source of water is stream.

The climate in Uzo-Uwani L.G.A. does not differ from that of the rain forest belt of Eastern Nigeria. Uzo-Uwani has many primary and secondary schools located in various areas of the community; these become sources for the sample study.

\subsection{Study Population}

Four schools consisting three secondary schools and one primary school each was randomly selected for investigation of prevalence of intestinal parasites among school children in Uzo-uwani Local Government Area. These schools include Uzo-uwani Secondary School Adani, Welfare Secondary School Opanda, Community Secondary School Nkpologu and Premier Primary School Ukpabi-Nibo.

Approval was obtained from The Principals and The Head Master of each school to collect faecal samples from children in their schools. A systematic random method was used to select a total number of 200 specimens. 50 children were selected from each school in this investigation. The study populations consist male and female from 4-18 years of age.

\subsection{Sample Collection}

Each participant was supplied with a clean, labeled wide mouth plastic specimen bottle with a cover and selected students for the study was properly instructed on how to collect and transfer their early 
morning faecal samples into the specimen bottles to avoid being contaminated using the applicator stick attached to the sample bottle cover, while this was done for younger pupils by their parents. The bottles were then collected from the pupils and students as they resume for morning class and faecal samples were immediately preserved with formalin and were finally taken to the laboratory for analysis.

Sample Collection was carried out in accordance to internationally best practice (Odoba et al., 2012: Pham-Duc et al., 2013).

A structured questionnaires on knowledge, attitude and practices used to obtained information from pupils and students (Ibidapo et al., 2005)

\subsection{Laboratory Examination of Faecal Samples}

The faecal specimens were examined macroscopical and microscopically in the laboratory, macroscopically examination for the presences of blood, mucus, adult worms and tapeworm segments.

The two different parasitological techniques used for the analysis were direct smear method and formal ether concentration technique.

\subsubsection{Direct Smear Method}

According to Arora and Arora (2010) direct smear method is achieved by mixing a small quantity (about $2 \mathrm{ng}$ ) of faecas in a drop of normal saline solution place on a clean glass slide. The faeces in the saline are emulsified and gross fibres or particles are removed. The emulsified faaecal smear is cover with cover slip. Air bubbles should be avoided by drawing one edge of the cover slide slightly into suspension and lowering it almost to the slide before letting it fall. The prepared slid is viewed under microscope using $\mathrm{x} 10$ and $\mathrm{x} 40$ objectives lens. The slid examine entirely by systematically moving the stage towards right, left, backward and forwards.

\subsubsection{Formal Ether Concentration Methods}

This method is based on the method described by Cheesbrough (2006), This method is carried out as follow:

With the help of a rod or stick emulsify approximately $1 \mathrm{~g}$ of faeces in about $4 \mathrm{ml}$ of $10 \%$ formal salin contained in a screw cap bottle or tube, mix by shaking for about 20 seconds. Sieve the emulsified faeces with 350 to 450 micrometer mesh collecting the sieved suspension in a beaker.

Transfer the suspension into a $15 \mathrm{ml}$ conical (centrifuge) tube made of story glass or polypropylene and further add about $4 \mathrm{ml}$ of diethyl ether, cap the tube and mix minute.

The homogenous solution is then place in the centrifuge and centrifuge at $3000 \mathrm{rpm}$ for 1 minute.

After centrifuging, the parasites most have sedimented to the bottom of the tube and feacal debris will be collected in a layer between the ether and formal water.

The second insoluble layer is loosen and top three layers will be discarded by rapidly inverting the tube, return the tube to its upright position and allow the fluid from the side drain to the bottom of the tube and mixed with the sediment on the bottom.

Pasteur pipette is use to mix the sediment and transfer all the sediment to a clean slid using and cover with a cover slide.

Examine under the microscope using $\mathrm{x} 10$ objectives with the condenser iris close sufficiently to give good contrast. The $\mathrm{x} 40$ objective is use to identify the small cyst and eggs.

Count the number of each type of parasite in entire preparation gives the approximate number of parasite per gram of faces.

\subsection{Identification of parasites}

The parasites were identified and classified in respect to their morphology by invesgator assisted by experienced laboratory technician and referring the parasitological manual (Cheesbrough, 2006).

\subsection{Statistical Analysis}

The data collected was cued in Microsoft Excel and exported to SPSS version 20 for analysis. Chi square was used to determine significant differences between variables. P-value $<0.05$ was 
considered significant .The results of the analysis were presented in figures and tables, interpreted in percentages with respect to age and sex of children examined.

\section{RESULTS}

\subsection{Demographic Characteristics of the Study Population}

This study enrolled two hundred (200) students in the study area, 50 were from each of the four different schools (Table 1). The study sampled equal number (100) of males and females. The age groups sampled in this study comprised the following; $5-7,8-10,11-13,14-16$ and $17-19$ years respectively. Out of 200 students who were screened for intestinal parasites, age brackets $8-10$ years and $17-19$ years had the highest $44(22 \%)$ and the least $36(18 \%)$ population respectively

Table1. Demographic characteristics of the study population

\begin{tabular}{|l|l|l|}
\hline Schools & Number Examined & Frequency \\
\hline Uzo-Uwani Secondary School, Adani & 50 & 25 \\
\hline Welfare Secondary School, Opanda & 50 & 25 \\
\hline Community Secondary School, Nkpologu & 50 & 25 \\
\hline Premier Primary School, Ukpabi-Nibo & 50 & 25 \\
\hline Total & 200 & 200 \\
\hline Gender & & \\
\hline Male & 100 & 50 \\
\hline Female & 100 & 50 \\
\hline Total & 200 & 100 \\
\hline Age Groups & & \\
\hline $5-7$ & 42 & 21 \\
\hline $8-10$ & 44 & 22 \\
\hline $11-13$ & 40 & 20 \\
\hline $14-16$ & 38 & 19 \\
\hline $17-19$ & 36 & 18 \\
\hline Total & 200 & 100 \\
\hline
\end{tabular}

\subsection{Prevalence of Intestinal Parasites among School Children in Uzo-Uwani L.G.A}

The intestinal parasites observed in this study are Hookworm, A. lumbricoides, T. trichiura, G. lamblia and E. histolytica (figure 1). Out of the 200 school children examined for intestinal parasites, 28(14.0\%) were infected with Hookworm and A. lumbricoides respectively, while 23 (11.5\%) and 17 (8.5\%) encountered T.trichuria and G.lamblia when compared with $21(10.5 \%)$ that were observed in E. histolytica. From figure 1, it can be seen that Hookworm and A. lumbricoides recorded equal and the highest prevalence $(14.0 \%)$ while $G$. lamblia had the lowest $(8.5 \%)$. There were significant differences in the prevalence of the parasites $(\mathrm{p}<0.05)$.

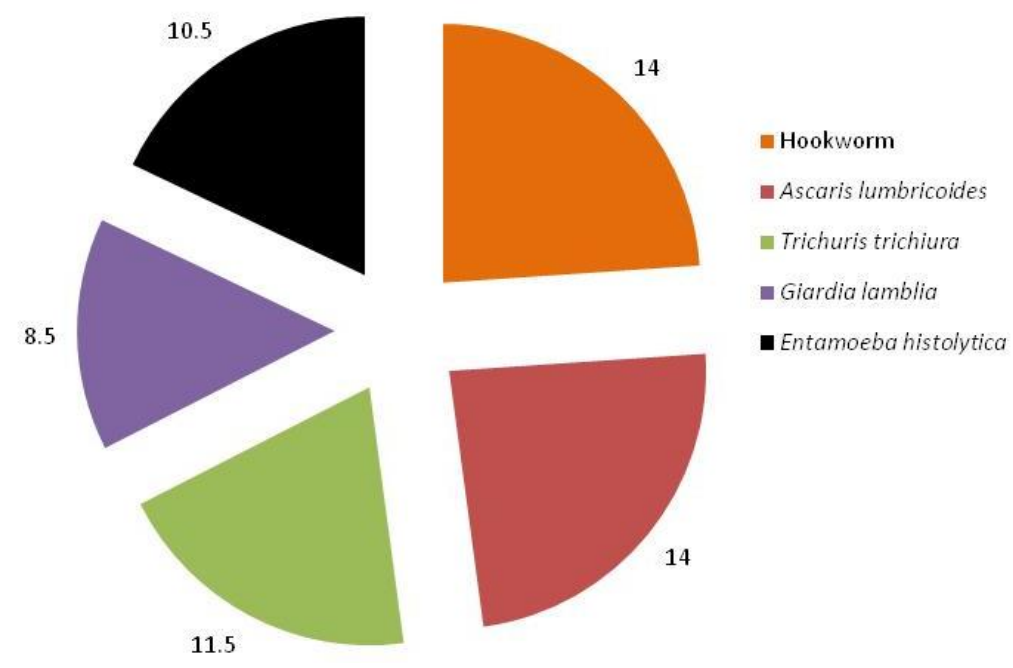

Figure1. Prevalence of intestinal parasites among school children in Uzo-Uwani L.G.A

\subsection{Prevalence of Intestinal Parasites in the Different Schools Sampled in Uzo Uwani L.G.A}


Prevalence of Intestinal Parasites among School Children in Uzo-Uwani Local Governemnt Area of Enugu State

The overall prevalence of intestinal parasites in different schools was represented in figure 3. Out of the 200 school children examined, 50 were from each of the four different schools (Table 2). Premier Primary School Ukpabi-Nibo had the highest prevalence for hookworm (18.0\%) and A. lumbricoides (16.0\%), while Community Secondary School Nkpologu and Uzo-Uwani Secondary School, Adani recorded the highest prevalence for T. trichiura (14.0\%) and E. histolytica (14.0\%) respectively (Table 2). However, Uzo-uwani secondary school and Primer Primary School Ukpabi-Nibo had the highest and equal prevalence of G. lamblia $(10.0 \%)$. There were no significant ( $p>0.05$ ) differences between the prevalence of infections among the schools sampled.

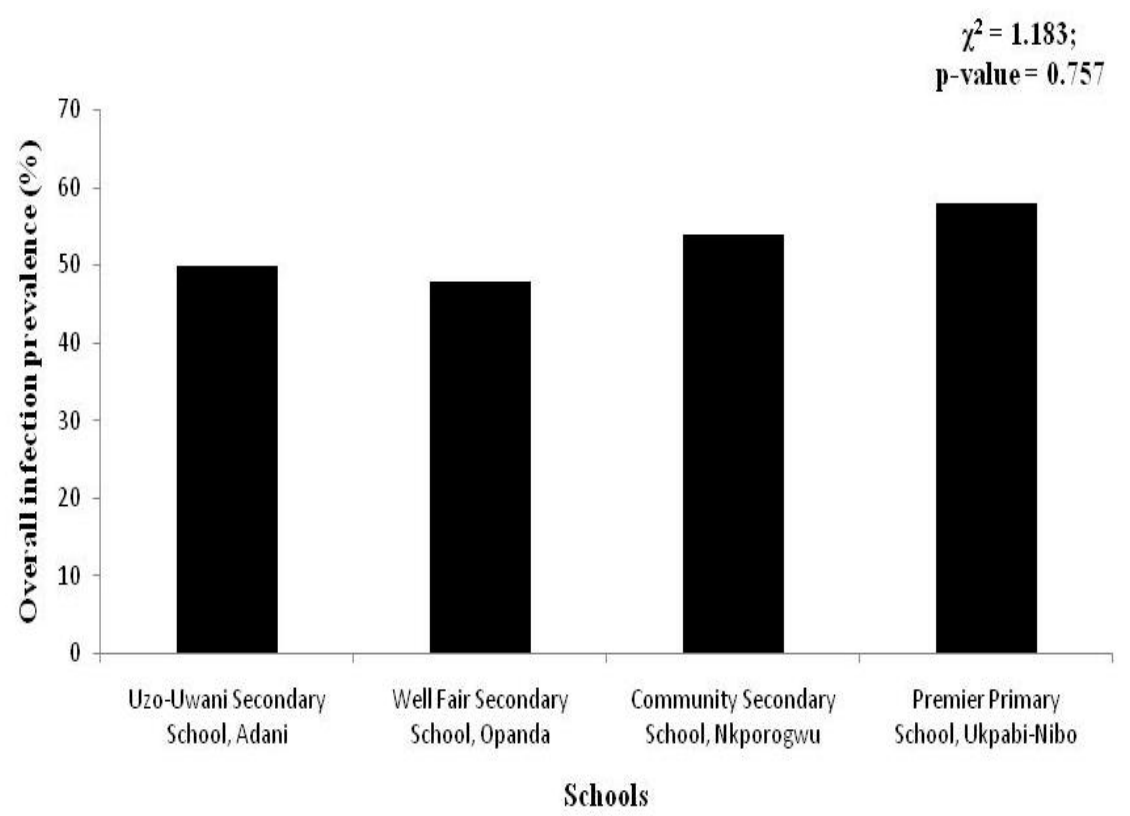

Figure3. Overall school-related prevalence of intestinal parasites in Uzo-Uwani L.G.A

Table2. Prevalence of intestinal parasites in the different schools sampled in Uzo-Uwani L.G.A

\begin{tabular}{|c|c|c|c|c|c|}
\hline \multirow[b]{2}{*}{ Schools $(n=50)$} & \multicolumn{5}{|l|}{ Parasites } \\
\hline & Hookworm & $\begin{array}{l}\text { Ascaris } \\
\text { lumbricoides }\end{array}$ & $\begin{array}{l}\text { Trichuris } \\
\text { trichiura }\end{array}$ & $\begin{array}{l}\text { Giardia } \\
\text { lamblia }\end{array}$ & $\begin{array}{l}\text { Entamoeba } \\
\text { histolytica }\end{array}$ \\
\hline $\begin{array}{l}\text { Uzo-Uwani Secondary School, } \\
\text { Adani }\end{array}$ & $6(12.0)$ & $7(14.0)$ & $4(8.0)$ & $5(10.0)$ & $7(14.0)$ \\
\hline $\begin{array}{lll}\text { Welfare } & \text { Secondary } & \text { School, } \\
\text { Opanda } & & \\
\end{array}$ & $5(10.0)$ & $7(14.0)$ & $6(12.0)$ & $4(8.0)$ & $4(8.0)$ \\
\hline $\begin{array}{ll}\text { Community } & \text { Secondary } \\
\text { School, Nkpologu } & \\
\end{array}$ & $8(16.0)$ & $6(12.0)$ & $7(14.0)$ & $3(6.0)$ & $6(12.0)$ \\
\hline $\begin{array}{l}\text { Premier Primary School, } \\
\text { Ukpabi-Nibo }\end{array}$ & $9(18.0)$ & $8(16.0)$ & $6(12.0)$ & $5(10.0)$ & $4(8.0)$ \\
\hline Total & $28(14.0)$ & $28(14.0)$ & $23(11.5)$ & $17(8.5)$ & $21(10.5)$ \\
\hline$\chi^{2}$ & 1.661 & 0.332 & 0.933 & 0.707 & 1.437 \\
\hline p-value & 0.646 & 0.954 & 0.817 & 0.872 & 0.697 \\
\hline
\end{tabular}

3.4 Distribution and Prevalence of Intestinal parasites among School Children

Out of the 200 school children sampled, equal number (100) were sampled for males and females respectively. Out of the 100 males examined, 11(11.0\%) had Hookworm, T. trichiura and E. histolytica infections respectively. From table 3, it could be observed that females recorded the highest prevalence of intestinal helminthes infections except in E. histolytica. There were no significant $(p>0.05)$ differences between sex in the prevalence of helminthes infection.

Table3. Sex distribution and prevalence of intestinal parasites among school children

\begin{tabular}{|l|l|l|l|l|l|l|}
\hline & & \multicolumn{3}{|l|}{ Parasites } \\
\cline { 3 - 7 } $\begin{array}{l}\text { Gender } \\
(\mathbf{n}=\mathbf{1 0 0})\end{array}$ & $\begin{array}{l}\text { Number } \\
\text { infected }\end{array}$ & Hookworm & $\begin{array}{l}\text { Ascaris } \\
\text { lumbricoides }\end{array}$ & $\begin{array}{l}\text { Trichuris } \\
\text { trichiura }\end{array}$ & $\begin{array}{l}\text { Giardia } \\
\text { lamblia }\end{array}$ & $\begin{array}{l}\text { Entamoeba } \\
\text { histolytica }\end{array}$ \\
\hline Male & $42(42.0)$ & $11(11.0)$ & $10(10.0)$ & $11(11.0)$ & $7(7.0)$ & $11(11.0)$ \\
\hline Female & $63(63.0)$ & $17(17.0)$ & $18(18.0)$ & $12(12.0)$ & $10(10.0)$ & $10(10.0)$ \\
\hline
\end{tabular}


GE Odo et al.

\begin{tabular}{|l|l|l|l|l|l|l|}
\hline \hline Total & $105(52.5)$ & $28(14.0)$ & $28(14.0)$ & $23(11.5)$ & $17(8.5)$ & $21(10.5)$ \\
\hline$\chi^{\mathbf{2}}$ & $\mathbf{8 . 8 4 2}$ & $\mathbf{1 . 4 9 5}$ & $\mathbf{2 . 6 5 8}$ & $\mathbf{0 . 0 4 9}$ & $\mathbf{0 . 5 7 9}$ & $\mathbf{0 . 0 5 3}$ \\
\hline p-value & $\mathbf{0 . 0 0 5}$ & $\mathbf{0 . 3 0 8}$ & $\mathbf{0 . 1 5 3}$ & $\mathbf{1 . 0 0 0}$ & $\mathbf{0 . 6 1 3}$ & $\mathbf{1 . 0 0 0}$ \\
\hline
\end{tabular}

3.5 Age Distribution and Prevalence of Intestinal Parasites among School Children

School Children between the ages of 5 - 19 were sampled. Children between the ages of $5-7$ had the highest prevalence of Hookworm $(19.0 \%)$ and E. histolytica (14.3\%) infections (Table 4). A. lumbricoides was most prevalent in the 8 - 10 age groups (20.5\%) while T. trichiura $(15.0 \%)$ and $G$. lamblia $(12.5 \%)$ were most prevalent in the $11-13$ age groups. The differences in prevalence between the different age groups were not statistically significant $(\mathrm{p}>0.05)$ for all the parasites recorded.

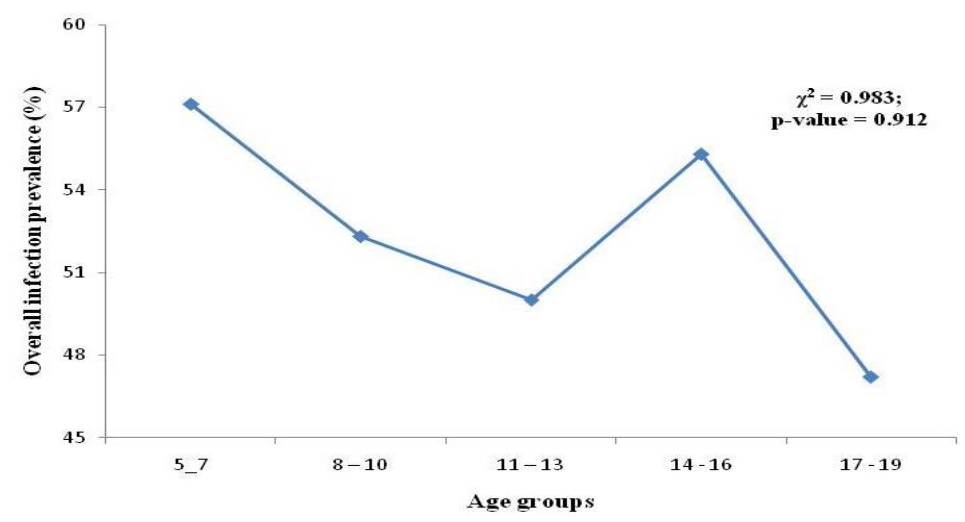

Figure4. Overall age-related prevalence of intestinal parasites in Uzo-Uwani L.G.A

Table4. Age Distribution and prevalence of intestinal parasites among school children in Uzo-Uwani L.G.A

\begin{tabular}{|c|c|c|c|c|c|c|}
\hline \multirow[b]{2}{*}{ Age groups } & \multirow[b]{2}{*}{$\begin{array}{l}\text { Number } \\
\text { Examined }\end{array}$} & \multicolumn{5}{|l|}{ Parasites } \\
\hline & & Hookworm & $\begin{array}{l}\text { Ascaris } \\
\text { lumbricoides }\end{array}$ & $\begin{array}{l}\text { Trichuris } \\
\text { trichiura }\end{array}$ & $\begin{array}{l}\text { Giardia } \\
\text { lamblia }\end{array}$ & $\begin{array}{l}\text { Entamoeba } \\
\text { histolytica }\end{array}$ \\
\hline $5-7$ & 42 & $8(19.0)$ & $7(16.7)$ & $5(11.9)$ & $3(7.1)$ & $6(14.3)$ \\
\hline $8-10$ & 44 & $7(15.9)$ & $9(20.5)$ & $4(9.1)$ & $2(4.5)$ & $4(9.1)$ \\
\hline $11-13$ & 40 & $5(12.5)$ & $4(10.0)$ & $6(15.0)$ & $5(12.5)$ & $3(7.5)$ \\
\hline $14-16$ & 38 & $4(10.5)$ & $6(15.8)$ & $3(7.9)$ & $3(7.9)$ & $5(13.2)$ \\
\hline $17-19$ & 36 & $4(11.1)$ & $2(5.6)$ & $5(13.9)$ & $4(11.1)$ & $3(8.3)$ \\
\hline Total & 200 & $28(14.0)$ & $28(14.0)$ & $23(11.5)$ & $17(8.5)$ & $21(10.5)$ \\
\hline$\chi^{2}$ & & 1.727 & 4.535 & 1.426 & 2.141 & 1.582 \\
\hline p-value & & 0.786 & 0.338 & 0.840 & 0.710 & 0.812 \\
\hline
\end{tabular}

\section{DisCUSSION}

E. histolytica and G. Camblia were the major protozoans intestinal parasites identified from the school children with the prevalence of $10.5 \%$ and $(8.5 \%)$ respectively.

Contrary to these findings, some workers in Nigeria and Overseas had earlier on reported higher prevalence rate of E histolytica. Eleni et al., (2014) reported 23.2\% prevalence rate with school children in Wukro Town, Eastern Ethiopia, while Padmaja et al., (2014) reported 63.27\% around Amalapuram India. Also Suresh et al., (2014) reported 61\% among school children in Kaski, Nepal. However similar findings had been reported by Biu et al., (2012) on the study carried out on the prevalence of intestinal parasites of school age pupils in Mafa L.G.A.of Borno State, Nigeria.

This study revealed that Hookworm and A. Lumbricoides recorded highest prevalence of $14.0 \%$ each, followed by $T$. trichuria $11.5 \%$. This was in agreement with the study done on the prevalence of intestinal parasitic infection in Wukro Town Eastern Trigray, Ethopia by Eleni et al (2014) which reported prevalence of A. Lumbricoide, Hookworm and T. trichuria as 3.9\%, 3.1\% respectively. This was in contrary by the study done by Onyeniran et al (2014) in Osogbo Nigeia which reported higher pretence of A. Lumbricoide 68.9\% than Hookworm 5.5\%.

The overall high prevalence $52.5 \%$ of intestinal parasites was similar to the high prevalence $(59.1 \%)$ reported by Usip et al (2013) among primary school pupils in Abak L.G.A. of Akwaibom State, Nigeria. Also similar to $76.2 \%$ prevalence among rural and sub-urban pupils in Gwagwada, Nigeria,studied by Auta et al (2014). This could be attributed to unhygienic behaviour(s) among children both at home and in school. Lack of sanitation facilities in these schools might have also contributed to the high 
prevalence. In all the selected schools, it was observed that there were no toilet facilities or, where present, they were not functional or no adequate water supply in the school. In contrary to this Odu et al (2013) reported $15.7 \%$ among primary school children in River State, Nigeria.

This study showed a marginally higher prevalence in females $63.0 \%$ when compared with males $42.0 \%$, there was not significant difference $(p>0.05)$ between the enteric parasitosis and sex. This suggested that intestinal parasites were in dependent of sex in Uzo Uwani L.G.A. Enugu State, Nigeria. This is comparable to what has been reported previously by other workers. Akingbade et al., (2013) also reported no significant difference in prevalence of intestinal parasite among children with diarrhoea in Ogun State, Nigeria. It agreed favorably with Suresh et al., (2014) who reported that gender wise parasitic infection rate was found to be almost equal among males and females. It also agreed with Umeh et al., (2015) who also report that difference in prevalence values of intestinal helminthes parasites between sexes in Uga, Anambra State, Nigeria were not statistically significant. These findings indicated that both sexes were equally exposed to entric parasites especially intestinal parasites. The findings also agreed with Eleni et al., (2014) who reported that intestinal parasitic infections were not sex dependent. The study disagrees with Biu et al., (2012) who reported that intestinal parasites were significantly higher in males than females.

This study revealed that age group of 8-10year had the highest prevalence $22.0 \%$ while the age group 17 19 years old had least prevalence $18 \%$. Though there was no statistical significant difference between the age group, but there was slight decline in prevalence as the age increased. This study was in agreement with Odu et al., (2013) who reported that prevalence of intestinal parasites were not age dependent. However this disagreed with Akingbade et al., (2013) who reported a significantly higher prevalence in age group 4-5 year old.

This study showed that Premier Primary School, Ukpabi-Nibo recorded highest prevalence 58.0\% followed by Community Secondary School Nkpologu 54.0\% then Uzo-Uwani Secondary School Adani $50.0 \%$, while Welfare Secondary School, Opanda has least prevalence of $48.0 \%$. Although there was no significant difference in intestinal parasites in the schools, but Premier Primary School who recorded highest prevalence could be that the school constituted more pupils who play within and outside the school with soil, bare footed and could pick objects on the ground or eat without washing hand.

\section{CONCLUSION}

In conclusion, it has been shown that prevalence of intestinal parasites in Uzo-Uwani L.G.A.of Enugu State is high. Public enlightenment, education, provision of good drinking water and water system type of toilet would be good attempts towards eradication of intestinal parasitic infection. For this effect, it could be opined that government and non-governmental organization should take all possible measures towards eradicating these intestinal parasitic infections through programme and mass chemotherapy.

\section{REFERENCES}

[1] Absar, A., Joseph, R., Rubino, M., and Khalid, I. (2010). The global war against intestinal parasite. International Journal of Infectious Disease, 14: 732 - 738.

[2] Akingbade, O. A., Akinjinmi, A. A., Ezechukwu, U. S., Okerentugba, P. O. and Okonko, I. O. (2013). Prevalence of intestinal parasites among children with diarrhea in Abeokuta, Ogun state, Nigeria. Researcher, 5(9): $66-73$.

[3] Arora, D. R. and Arora, B. (2010). Medical Parasitology. Third Edition. Bangalore, India, CBS Publisher New Delhi.

[4] Auta, T., Wartu J., R., Jibiya, B. A. and Jabi, A. M. (2014). A comparative study on the prevalence of intestinal helminthes among rural and sub-urban pupils in Gwagwada, Nigeria. Journal of Parasitology and Vector Biology, 5(6): 87 - 91.

[5] Biu, A. A., Kyari, F. and John, W. M. (2012). Prevalence of intestinal parasites in school aged pupils in Mafa Local Government Area of Borno State, Nigeria. Journal of Medicine and Applied Biosciences, 4 : 54 - 55

[6] Brooker, S., Clement, A. C. and Bundy, D. A. (2006). Global epidemiology, ecology and control of soil- transmitted helminth infections. Advance in Parasitology, 62: $221-261$. 
[7] Cheesbrough, M. (2006). District Laboratory Practice in Tropical Countries. Part 2. Cambridge University Press p - 357.

[8] Childer, K., Palmieri, J., Sampson, M., and Brunet, D. (2014). A survey of the prevalence of gastro intestinal parasites in children from Veron, Dominican Republic. Research Reports in Tropical Medicine, 5: 45 - 53.

[9] Damen, J. G., Lar, P., Mbaawuga, E. M. and Nyary, B. W. (2010). A comparative study on the prevalence of intestinal helminthes in de-wormed and non-dewormed students in rural area of North-central Nigeria. Laboratory Medicine, 41: 585 - 589.

[10] Eleni, K., Sissay, M., Ameha, K. and Mulugeta, D. (2014). Prevalence of intestinal parasitic infections and their association with anthropometric measurements of school children in selected primary schools, Wukro Town, Eastern Tigray, Ethiopia. International Journal of Current Microbiology and Applied Sciences, 52: 43 - 48.

[11] Enimien, O.J., Fana, S.A. and Emmanuel W.B. (2014). Intestinal helminthic infection in Numan (Northeast Nigeria)., International Journal of Innovation and Applied Study,5(2): 102 - 105.

[12] Ibidapo, C. A., Mafe, M. A. and Awebimpe, O. L. (2005). Comparison of the three diagnostic methods for determination of prevalence of urinary schistosomiasis among residents and pupils of Badagry Area of Lagos State, Nigeria. African Journal of Biotechnology 4(1): 1315 - 1328.

[13] Michael, O. H., John, H. and Pierol, O. (2010). Epidemiology and control of human gastrointestinal parasites in children. National Library of Medicine and National Institute of Health, 8: 219-234.

[14] Odoba, M. B. Otalu, O. and Balegun, J. B. (2012). Prevalence of helminth parasite eggs in pupil and playing grounds of some selected primary schools in Zaria, Nigeria. World Journal for Lij Science and Medical Research, 2(5): 192.

[15] Odu, N. N., Elechi, V. I and Okonko, I. O. (2013). Prevalence of intestinal helminthes infection among primary school in urban and semi-urban area in Port-Harcourt, River State, Nigeria. World Rural Observation, 5(1): $52-61$.

[16] Onyeniran, O. A., Ogurongbe, O., Oladipo, E. K., Afolabi, A. Y. and Ajayi, O. O. (2014). Intestinal parasitic infection among primary school pupils in Osogbo, Nigeria. Journal of Dental and Medical Sciences, 13, :, 96, -,101.

[17] Onyishi, G. C., and Okafor, F. C. (2005). Helminth Parasitic diseases status of school children within the Anambra river basin irrigation project area. Biological Research Doirnal 3(1): 93 - 98.

[18] Padmaja, N, Sai swaroop, P. and Nageswararao, P. (2014). Prevalence of intestinal parasitic infections among school children in and around Amalapuram. Journal of Public Health and Medical Research, 2(2): 36 - 38.

[19] Pham-Duc, P., Nguye n-Viet, H., Hattendorf, J., Zinsstag, J. Phung-Dac, C., Zurbriigg, C. and odermatt, P. (2013). Ascaris lumbricoides and Trichuris trichiura infections associated with wastewater and human excreta using agriculture in Viettan. Parasitology International, 62: 172 180.

[20] Suresh, J., Dhaka, R. P., Bwhnu, R. T., Jay, P. S., Ravin, B. and Shraddha, U. (2014). Prevalence $\sim f$ intestinal parasites among school children of Bharatppkharia V.D.C. Kaski, Nepal. Brit Microbiology Research Journal, 4(9): 1007 - 1012.

[21] Umeh, C., Mbanugo, J. I. and Ezeugoigwe, N. (2015). Prevalence of intestinal helminthes parasites in stools of nursery and primary school pupils in Uga, Anambra State, Nigeria. Sky Journal of Microbiology Research, 3(1): 006 - 010.

[22] Usip, L., Esiest, P. and David, N. C. (2013). The prevalence of human intestinal helminthes and the efficacy of anthelmentic lavamisole drug in Abak Local Government Area of Akwaibom State, Nigeria. Basic Researcher Journal of Medicine and Clinical Sciences, 2(5): 52 - 58. 